\title{
LOCATION OF “REELER" IN LINKAGE GROUP III OF THE MOUSE
}

\author{
D. S. FALCONER \\ Animal Breeding and Genetics Research Organisation, \\ Institute of Animal Genetics, Edinburgh, 9
}

Received 15.ix.5I

"REeleR" $(r l)$ is a recessive gene of the house mouse which impairs locomotion through a disturbance of balance. It has been tested for linkage with a few markers, with which it was found to segregate independently (Falconer, I95I). The loci of macrocytic anæmia $(W)$ and of luxate $(l x)$, in linkage group III were, however, not included in these tests, and subsequent work has shown reeler to be linked with these two loci, the order being $W-l x-r l$, and the recombination I 6 per cent. with $l x$ and 29 per cent. with $W$. This linkage is interesting in that it adds another 16 units to this already long linkage group, but its practical value in linkage studies is not likely to be great on account of the poor breeding performance of reeler homozygotes. On the other hand the linkage may have some value as an aid in the maintenance of reeler stocks.

The data which give evidence of the linkage come from four types of mating, of which the parental genotypes are shown in table $\mathrm{I}$. The viable allele of macrocytic anæmia $\left(W^{v}\right)$ was used in the tests. Some of the matings segregated all three loci, but in the presentation and analysis of the data the two tests, $r l$ with $W^{v}$ and $r l$ with $l x$, are treated separately. Reeler segregated always from an intercross; the other loci segregated either from an intercross or a backcross, and in each case the coupling and repulsion phases were represented, though not always equally. The distribution of the progeny of each type of mating among the different phenotypic classes is given in table $\mathrm{I}$.

The analysis of the data was made by means of Fisher's scoring system (Fisher, 1946), and the scores (S) and amounts of information (I) for each type of mating are set out in table 2. The columns headed I are based on scoring coefficients calculated for the assumption of free recombination $(p=0.5)$ and undisturbed single-factor segregations. The highly significant values of $\chi^{2}$ disprove the hypothesis of independent segregation beyond doubt, and the analyses indicate approximate recombination fractions of 35 per cent. with $W^{v}$ and 25 per cent. with $l x$.

The more precise estimation of the recombination fractions is complicated by the faulty single-factor segregations of both $W^{v}$ and $l x$. There is a deficiency of $W^{v} W^{v}$ phenotypes which may be attributed 
to prenatal mortality, and a deficiency also of $l x l x$ phenotypes which may be attributed, in part at least, to linkage in coupling with $W^{v}$.

TABLE I

Observed segregation of $\mathrm{rl}$ with $\mathrm{W}^{v}$ and with $\mathrm{lx}$

\begin{tabular}{|c|c|c|c|c|c|c|c|c|c|}
\hline \multirow{2}{*}{$\begin{array}{l}\text { Type of } \\
\text { mating }\end{array}$} & \multicolumn{2}{|c|}{ Genotype of } & \multicolumn{3}{|c|}{+} & \multicolumn{3}{|c|}{$r l$} & \multirow{2}{*}{ Total } \\
\hline & Female & Male & $W^{\natural} W^{v}$ & $W^{v}+$ & ++ & $W^{v} W^{v}$ & $W^{v}+$ & ++ & \\
\hline A & $\frac{W^{v}+}{+r l}$ & $\frac{W^{v}+}{+r l}$ & 6 & 22 & II & 2 & 4 & 9 & 54 \\
\hline B & $\frac{W^{v} r l}{++}$ & $\frac{W^{v} r l}{++}$ & I 3 & 85 & 33 & 10 & 12 & 2 & 555 \\
\hline C & $\frac{+r l}{t+}$ & $\frac{W^{v}+}{+r l}$ & $\cdots$ & I 3 & 7 & $\cdots$ & 2 & 8 & 30 \\
\hline D & $\frac{+n}{+t}$ & $\frac{W^{v} r l}{++}$ & ... & 33 & $5^{\mathrm{I}}$ & $\ldots$ & I3 & II & $x 08$ \\
\hline & & & $l x l x$ & $l x+$ & + & $l x l x$ & $l x+$ & + & \\
\hline A & $\frac{l x+}{+r l}$ & $\frac{l x+}{+r l}$ & Io & $4^{I}$ & 19 & 2 & 2 & 25 & 99 \\
\hline B & $\frac{l \times r l}{++}$ & $\frac{l x r l}{++}$ & 7 & 22 & $6 \mathrm{r}$ & 7 & I & 5 & 103 \\
\hline C & $\frac{l x+}{+r l}$ & $\frac{++}{+r l}$ & $\cdots$ & 14 & 29 & $\cdots$ & o & 6 & 49 \\
\hline D & $\frac{l x}{t+} \frac{n t}{+}$ & $\frac{+n}{++}$ & $\cdots$ & 9 & $3^{2}$ & $\ldots$ & 3 & 8 & $5^{2}$ \\
\hline
\end{tabular}

In addition, $l x$ shows normal overlapping of the heterozygote class. In order to make allowance for these disturbed segregations the scoring coefficients were recalculated on the basis of the observed frequencies of the $W^{v} W^{v}, l x l x$, and $l x+$ phenotypic classes. Thus the expected frequencies for the single-factor segregations were as follows : for intercrosses,

$\begin{array}{llllllll}\text { Phenotype . } & . W^{v} W^{v} W^{v}+ & ++ & l x l x & l x+ & \overbrace{l x+}^{+}++ \\ \text {Expectation . } & .0 .15 & 0.56 & 0.29 & 0.13 & 0.32 & 0.26 & 0.29\end{array}$

and for luxate in backcrosses,

$$
\begin{aligned}
& \text { Phenotype } \cdot l x+\overbrace{l x+++}^{+} \\
& \text {Expectation . } \begin{array}{llll}
\quad .0 .26 & 0.24 & 0.50
\end{array}
\end{aligned}
$$

The recombination values assumed in the re-scoring were those indicated by the first analysis, 35 per cent. with $W^{v}$ and 25 per cent. with $l x$. The scores and information obtained with the revised coefficients are given in the columns headed 2 in table 2. The 
estimates of the recombination fractions are now substantially lower than those obtained from the first analysis, 30 per cent. with $W^{v}$ and 16 per cent. with $l x$, the reduction being due to the removal

TABLE 2

Analysis of the data in table $I$

\begin{tabular}{|c|c|c|c|c|c|c|c|c|c|c|c|c|}
\hline \multirow{3}{*}{$\begin{array}{l}\text { Type of } \\
\text { mating }\end{array}$} & \multicolumn{6}{|c|}{$W^{v}$} & \multicolumn{6}{|c|}{$l x$} \\
\hline & \multicolumn{2}{|c|}{$(p=0.50)$} & \multicolumn{2}{|c|}{$\left(p={ }^{2} \cdot 35\right)$} & \multicolumn{2}{|c|}{$\left(p=\frac{3}{0.30}\right)$} & \multicolumn{2}{|c|}{$\left(p=\begin{array}{c}\mathrm{I} \\
(p=50)\end{array}\right.$} & \multicolumn{2}{|c|}{$\left(p=\frac{2}{=0 \cdot 25}\right)$} & \multicolumn{2}{|c|}{$\begin{array}{c}3 \\
(p==0 \cdot 15)\end{array}$} \\
\hline & $\mathrm{S}$ & I & S & I & S & I & S & I & $\mathrm{S}$ & I & $S$ & I \\
\hline $\begin{array}{l}\text { A } \\
\text { B } \\
\text { C } \\
\text { D }\end{array}$ & $\begin{array}{l}21 \\
59 \\
16 \\
16\end{array}$ & $\begin{array}{r}144 \\
4^{13} \\
40 \\
144\end{array}$ & $\begin{array}{r}0 \\
34 \\
9 \\
-5\end{array}$ & $\begin{array}{r}I 6 I \\
410 \\
43 \\
155\end{array}$ & $\begin{array}{r}-10 \\
21 \\
7 \\
-13\end{array}$ & $\begin{array}{r}188 \\
463 \\
46 \\
165\end{array}$ & $\begin{array}{r}80 \\
80 \\
2 \\
5\end{array}$ & $\begin{array}{r}264 \\
275 \\
65 \\
69\end{array}$ & $\begin{array}{r}28 \\
19 \\
4 \\
-3\end{array}$ & $\begin{array}{r}178 \\
309 \\
34 \\
22\end{array}$ & $\begin{array}{r}\mathrm{I} \\
-\mathrm{I} 6 \\
4 \\
-5\end{array}$ & $\begin{array}{r}263 \\
514 \\
51 \\
22\end{array}$ \\
\hline $\begin{array}{l}\text { Total } \\
\chi_{\text {Estimated }}^{2} \\
\text { recombination } \\
\text { Standard error }\end{array}$ & $\begin{array}{r}x \leq 2 \\
1 \\
35\end{array}$ & $74 I$ & $\begin{array}{r}3^{8} \\
I \\
30\end{array}$ & 769 & $\begin{array}{r}5 \\
0 \cdot c \\
2 . \\
3.4\end{array}$ & 862 & 167 & 673 & 48 & $\begin{array}{l}543 \\
\cdot 2 \\
\%\end{array}$ & $\begin{array}{r}-6 \\
o \\
\end{array}$ & $\begin{array}{l}850 \\
04 \\
\% \\
\%\end{array}$ \\
\hline
\end{tabular}

$\mathrm{S}=$ Score. $\quad \mathrm{I}=$ Amount of information.

of the disturbing effects of the aberrant single-factor segregations. A third analysis based on the revised recombination fractions was made, and the results are given in the columns headed 3 in table 2. The values of $\chi^{2}$ testing deviation from the assumed recombination fractions are now very small, and the final estimates of recombination with their standard errors are

$$
\begin{aligned}
& W^{v}-r l: p=29 \pm 3.4 \text { per cent. } \\
& l x-r l: p=16 \pm 3.4 \text { per cent. }
\end{aligned}
$$

These values accord well with the recombination of $17 \cdot 7 \pm 1.2$ per cent. observed for $W^{v}$ with $l x$ (Carter, 1951), and the order of the three loci is proved to be $W^{v}-l x-r l$.

\section{REFERENCES}

CARTER, T. G. 1951. The genetics of luxate mice. II. Linkage and independence. 7. Genet., 50, 300-306.

FALCONER, D. s. 1951. Two new mutants, "Trembler" and "reeler," with neurological actions in the house-mouse (Mus musculus, L.). F. Genet., 5o, 192201.

FISHER, R. A. 1946. A system of scoring linkage data, with special reference to the pied factors in mice. Amer. Nat., $80,5^{68-578 .}$ 